\title{
Front Matter: Volume 10825
}

, "Front Matter: Volume 10825," Proc. SPIE 10825, Quantum and Nonlinear Optics V, 1082501 (14 November 2018); doi: 10.1117/12.2522340

SPIE. Event: SPIE/COS Photonics Asia, 2018, Beijing, China 


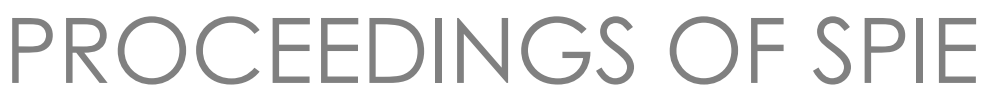

\title{
Quantum and Nonlinear Optics V
}

\author{
Qihuang Gong \\ Guang-Can Guo \\ Byoung S. Ham \\ Editors
}

\section{1-13 October 2018 \\ Beijing, China}

\author{
Sponsored by \\ SPIE \\ COS_Chinese Optical Society
}

Cooperating Organizations

Tsinghua University (China) • Peking University (China) • University of Science and Technology of China (China) • Zhejiang University (China) - Tianjin University (China) - Beijing Institute of Technology (China) • Beijing University of Posts and Telecommunications (China) - Nankai University (China) - Changchun University of Science and Technology (China) University of Shanghai for Science and Technology (China) • Capital Normal University (China) • Huazhong University of Science and Technology (China) - Beijing Jiaotong University (China) - Shanghai Institute of Optics and Fine Mechanics (China) - Changchun Institute of Optics and Fine Mechanics (China) - Institute of Semiconductors (China) - Institute of Optics and Electronics (China) - Institute of Physics (China) • Shanghai Institute of Technical Physics (China) • China Instrument and Control Society (China) - Optoelectronics Technology Committee, COS (China) • Optical Society of Japan (Japan) • Optical Society of Korea (Korea, Republic of) • The Australian Optical Society (Australia) • Optics and Photonics Society of Singapore (Singapore) • European Optical Society

Supporting Organizations

CAST_China Association for Science and Technology (China)

NSFC-National Nature Science Foundation (China)

Published by

SPIE

Volume 10825 
The papers in this volume were part of the technical conference cited on the cover and title page. Papers were selected and subject to review by the editors and conference program committee. Some conference presentations may not be available for publication. Additional papers and presentation recordings may be available online in the SPIE Digital Library at SPIEDigitallibrary.org.

The papers reflect the work and thoughts of the authors and are published herein as submitted. The publisher is not responsible for the validity of the information or for any outcomes resulting from reliance thereon.

Please use the following format to cite material from these proceedings:

Author(s), "Title of Paper," in Quantum and Nonlinear Optics V, edited by Qihuang Gong, GuangCan Guo, Byoung S. Ham, Proceedings of SPIE Vol. 10825 (SPIE, Bellingham, WA, 2018) Seven-digit Article CID Number.

ISSN: 0277-786X

ISSN: 1996-756X (electronic)

ISBN: 9781510622487

ISBN: 9781510622494 (electronic)

Published by

SPIE

P.O. Box 10, Bellingham, Washington 98227-0010 USA

Telephone +1 3606763290 (Pacific Time) · Fax +1 3606471445

SPIE.org

Copyright (C) 2018, Society of Photo-Optical Instrumentation Engineers.

Copying of material in this book for internal or personal use, or for the internal or personal use of specific clients, beyond the fair use provisions granted by the U.S. Copyright Law is authorized by SPIE subject to payment of copying fees. The Transactional Reporting Service base fee for this volume is $\$ 18.00$ per article (or portion thereof), which should be paid directly to the Copyright Clearance Center (CCC), 222 Rosewood Drive, Danvers, MA 01923. Payment may also be made electronically through CCC Online at copyright.com. Other copying for republication, resale, advertising or promotion, or any form of systematic or multiple reproduction of any material in this book is prohibited except with permission in writing from the publisher. The CCC fee code is 0277$786 \mathrm{X} / 18 / \$ 18.00$.

Printed in the United States of America.

Publication of record for individual papers is online in the SPIE Digital Library.

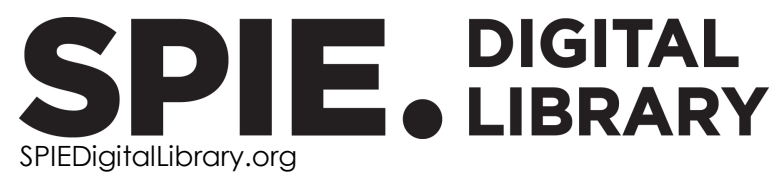

Paper Numbering: Proceedings of SPIE follow an e-First publication model. A unique citation identifier (CID) number is assigned to each article at the time of publication. Utilization of CIDs allows articles to be fully citable as soon as they are published online, and connects the same identifier to all online and print versions of the publication. SPIE uses a seven-digit CID article numbering system structured as follows:

- The first five digits correspond to the SPIE volume number.

- The last two digits indicate publication order within the volume using a Base 36 numbering system employing both numerals and letters. These two-number sets start with $00,01,02,03,04$, 05, 06, 07, 08, 09, 0A, OB ... 0Z, followed by 10-1Z, 20-2Z, etc. The CID Number appears on each page of the manuscript. 


\title{
Contents
}

\author{
$\checkmark \quad$ Authors \\ vii Symposium Committees \\ xi Conference Committee
}

QUANTUM MEASUREMENT AND QUANTUM COMPUTATION

10825 OB Precision patterning sub-nanometrology relied up pico-meter quantum sensing approach [10825-9]

\section{MATTER-LIGHT CORRELATIONS AND COHERENCE I}

10825 OD Steering of entangled photon states with nonlinear metamaterials [10825-11]

10825 OF Nonclassicality and entanglement for continuous-variable quantum information (Invited Paper) [10825-13]

\section{POSTER SESSION}

$1082510 \quad$ Interference effect in the photodetachment of silver anions by short femtosecond laser field [10825-34]

$1082511 \quad$ Numerical simulation and experimental studies on soliton self-frequency shift in single-mode optical fiber [10825-35]

1082512 Optical frequency comb generation with widely and precisely frequency space [10825-36]

$1082513 \quad$ Ultra-high group index slow light with optical buffering performance in photonic crystal waveguide coupled with cavity [10825-37]

$1082514 \quad$ Influence of atomic densities on propagation property for femtosecond Gaussian pulse in a three-level $\Lambda$-type atomic medium [10825-38]

1082515 The ultra-stable microwave based on ultra-stable laser with robustness and long term stability [10825-39]

1082516 Dual-wavelength eye-safe optical parametric oscillator intracavity driven by a coaxially end pumped laser [10825-40] 
1082517 Propagation of ultrashort dichromatic solitons in a cascade three-level system [10825-41]

1082518 Coherence automatic adjustment of the optical pulses inside mode-lock fiber laser cavity [10825-42]

$1082519 \quad$ New generation regimes in mode-locked fibre lasers with controllable radiation intensity distribution along the cavity [10825-43]

10825 1B Analysis of underwater target detection based on entangled Fock state interference [10825-45]

10825 1D Localization in a synthetic photonic lattice with varying coupling ratio [10825-47]

$10825 \mathrm{IE} \quad$ Analysis of the CW single frequency laser radiation from UV to near-IR generated by intracavity second harmonic generation of the resonant wave in singly resonant optical parametric oscillator under collimated Gaussian beam approximation [10825-48]

10825 IF A monolithic readout circuit for high-frequency sine wave gating single-photon detection [10825-49]

$1082511 \quad$ Study of coherence effects in an inverted Y-type four-level system [10825-52] 


\section{Authors}

Numbers in the index correspond to the last two digits of the seven-digit citation identifier (CID) article numbering system used in Proceedings of SPIE. The first five digits reflect the volume number. Base 36 numbering is employed for the last two digits and indicates the order of articles within the volume. Numbers start with 00, 01, 02, 03, 04, 05, 06, 07, 08, 09, OA, OB...0Z, followed by 10-1Z, 20-2Z, etc.

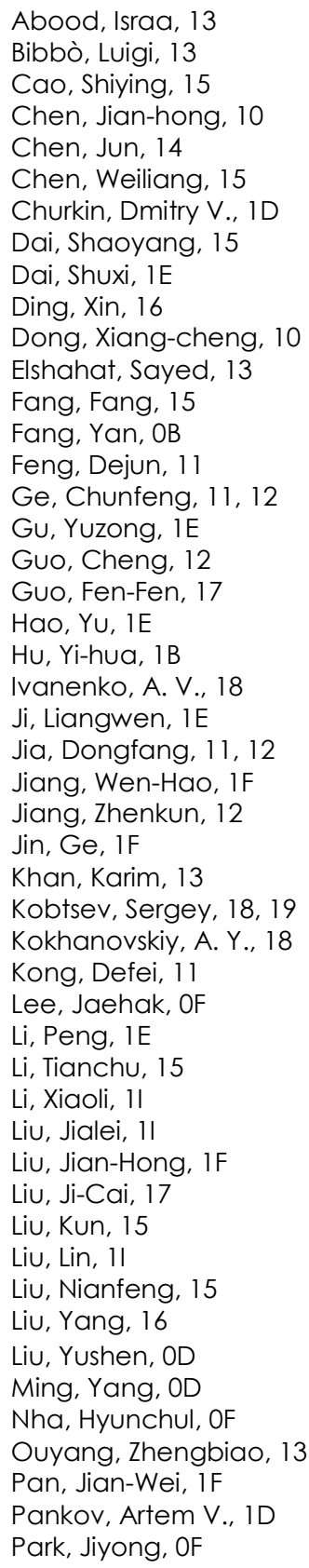

Qiao, Hongzhan, 16

Shi, Jie, 16

Shi, Yafang, 11

Smirnov, Sergey, 19

Tang, Jie, OD

Turitsyn, S. K., 18

Vatnik, llya D., 1D

Wang, Longlong, 11

Wang, Ying, 11

Wang, Zhaoying, 11, 12

Wang, Zhendong, 14

Wu, Zhenkun, 1E

Xie, Taoran, 12

$X U$, Degang, 16

$\mathrm{XU}$, Shi-long, 1B

Yadav, Ashish, 13

Yang, Tianxin, 11

Yao, Jianquan, 16

Yuan, Quan, 12

Yuan, Xiaoxian, 11

Zhang, Jun, IF

Zhang, Tian-yun, 10

Zhang, Wang, OD

Zhao, Xiaohui, 11

Zhao, Ya-nan, 17

Zheng, Xiao-ping, 10

Zhong, Kai, 16

Zhou, Wenguang, 11

Zhu, Baohua, IE 
Proc. of SPIE Vol. 10825 1082501-6

Downloaded From: https://www.spiedigitallibrary.org/conference-proceedings-of-spie on 26 Apr 2023 Terms of Use: https://www.spiedigitallibrary.org/terms-of-use 


\title{
Symposium Committees
}

\author{
General Chairs
}

Maryellen Giger, President, SPIE and The University of Chicago (United States)

Qihuang Gong, President, Chinese Optical Society and Peking University (China)

General Co-chairs

Arthur Chiou, National Yang-Ming University (Taiwan, China)

Guangcan Guo, Past President, Chinese Optical Society and University of Science and Technology of China (China)

Zejin Liu, Vice President, Chinese Optical Society and National University of Defense Technology (China)

Technical Program Chairs

Ruxin Li, Vice President, Chinese Optical Society and Shanghai Institute of Optics and Fine Mechanics (China)

Xingde Li, Johns Hopkins University (United States)

Technical Program Co-chairs

Tianchu Li, National Institute of Metrology (China)

Wei Huang, Northwestern Polytechnical University (China)

Ying Gu, Vice President, Chinese Optical Society and PLA General Hospital (China)

Huilin Jiang, Changchun University of Science and Technology (China)

Local Organizing Committee Chair

Xu Liu, Secretary General, Chinese Optical Society and Zhejiang University (China) 
Local Organizing Committee Co-chairs

Wenqing Liu, Vice President, Chinese Optical Society and Anhui Institute of Optics and Fine Mechanics (China)

Guobin Fan, China Academy of Engineering Physics (China)

Local Organizing Committee

Xiaomin Ren, Vice President, Chinese Optical Society and Beijing University of Posts and Telecommunications (China)

Suotang Jia, Vice President, Chinese Optical Society and Shanxi University (China)

Wenjie Wang, Vice President, Chinese Optical Society and Sunny Group Company, Ltd. (China)

Qingming Luo, Huazhong University of Science and Technology (China)

Ping Jia, Changchun Institute of Optics, Fine Mechanics and Physics (China)

Wei Zhao, Xi'an Institute of Optics and Precision Mechanics (China)

Yudong Zhang, Chengdu Branch, Chinese Academy of Sciences (China)

Ninghua Zhu, Institute of Semiconductors (China)

Yongtian Wang, Beijing Institute of Technology (China)

Xiaocong Yuan, Shenzhen University (China)

Limin Tong, Zhejing University (China)

Weimin Chen, Chongqing University (China)

Yidong Huang, Tsinghua University (China)

Tiegen Liu, Tianjin University (China)

Zhiping Zhou, Peking University (China)

Changhe Zhou, Jinan University (China)

Yiping Cui, Southeast University (China)

Zhongwei Fan, Academy of Optoelectronics, CAS (China)

Xiaoying Li, Tianjin University (China)

Yan Li, Deputy Secretary General, Chinese Optical Society and Peking University (China)

Caiwen Ma, Xi'an Institute of Optics and Precision Mechanics (China)

Xinliang Zhang, Huazhong University of Science and Technology (China)

Jianxin Chen, Fujian Normal University (China)

Yihua Hu, College of Electronic Engineering, National Univ. of Defense Technology (China) 
Secretaries-General

Bo Gu, Deputy Secretary General, Chinese Optical Society (China)

Hong Yang, Deputy Secretary General, Chinese Optical Society and

Peking University (China)

Executive Organizing Committee

David J. Bergman, Tel Aviv University (Israel)

Qionghai Dai, Tsinghua University (China)

Keisuke Goda, The University of Tokyo (Japan)

Qihuang Gong, Peking University (China)

Ying Gu, Chinese PLA General Hospital (China)

Guang-Can Guo, University of Science and Technology of China

(China)

Byoung S. Ham, Gwangju Institute of Science and Technology

(Korea, Republic of)

Sen Han, University of Shanghai for Science and Technology (China) and Suzhou H\&L Instruments LLC (China)

Werner H. Hofmann, Technische Universität Berlin (Germany)

Minghui Hong, National University of Singapore (Singapore)

Bahram Jalali, University of California, Los Angeles (United States)

Shibin Jiang, AdValue Photonics, Inc. (United States)

Satoshi Kawata, Osaka University (Japan)

Tina E. Kidger, Kidger Optics Associates (United Kingdom)

Baojun Li, Jinan University (China)

Ming Li, Institute of Semiconductors (China)

Ruxin Li, Shanghai Institute of Optics and Fine Mechanics (China)

Xingde Li, Johns Hopkins University (United States)

Jian Liu, PolarOnyx, Inc. (United States)

Tiegen Liu, Tianjin University (China)

Yongfeng Lu, University of Nebraska-Lincoln (United States)

Qingming Luo, Huazhong University of Science and Technology (China)

Yuji Sano, ImPACT (Japan)

Yunlong Sheng, Université Laval (Canada)

Kebin Shi, Peking University (China)

Tsutomu Shimura, The University of Tokyo (Japan)

Upendra N. Singh, NASA Langley Research Center (United States)

Michael G. Somekh, The Hong Kong Polytechnic University

(Hong Kong, China)

Yuguo Tang, Suzhou Institute of Biomedical Engineering and

Technology (China)

Masahiko Tani, University of Fukui (Japan)

Kimio Tatsuno, Koga Research Institute, Ltd. (Japan)

Kevin K. Tsia, The University of Hong Kong (Hong Kong, China)

Kazumi Wada, Massachusetts Institute of Technology (United States) 
Yongtian Wang, Beijing Institute of Technology (China)

Rongshi Xiao, Beijing University of Technology (China)

Hongxing Xu, Wuhan University (China)

Toru Yoshizawa, Tokyo University of Agriculture and Technology

(Japan) and 3D Associates (Japan)

Changyuan Yu, The Hong Kong Polytechnic University

(Hong Kong, China)

Chongxiu Yu, Beijing University of Posts and Telecommunications (China)

Xiao-Cong Yuan, Shenzhen University (China)

Xiaoyan Zeng, Huazhong University of Science and Technology (China)

Cunlin Zhang, Capital Normal University (China)

Song Zhang, Purdue University (United States)

Xi-Cheng Zhang, University of Rochester (United States)

Xinliang Zhang, Wuhan National Laboratory for Optoelectronics (China)

Xuping Zhang, Nanjing University (China)

Changhe Zhou, Shanghai Institute of Optics and Fine Mechanics (China)

Zhiping Zhou, Peking University (China)

Dan Zhu, Huazhong University of Science and Technology (China)

Ning Hua Zhu, Institute of Semiconductors (China) 


\title{
Conference Committee
}

\author{
Conference Chairs \\ Qihuang Gong, Peking University (China) \\ Guang-Can Guo, University of Science and Technology of China \\ (China) \\ Byoung S. Ham, Gwangju Institute of Science and Technology \\ (Korea, Republic of) \\ Conference Program Committee \\ Yiping Cui, Southeast University (China) \\ Luming Duan, California Institute of Technology (United States) \\ Qiongyi He, Peking University (China) \\ Osamu Hirota, Tamagawa University (Japan) \\ Hyunseok Jeong, Seoul National University (Korea, Republic of) \\ François Kajzar, University Politehnica of Bucharest (Romania) \\ Jianwei Pan, University of Science and Technology of China (China) \\ Kunchi Peng, China International Science and Technology \\ Cooperation (China) \\ Kebin Shi, Peking University (China) \\ Jingjun Xu, Nankai University (China) \\ Zuyan Xu, Technical Institute of Physics and Chemistry (China) \\ Toyohiko Yatagai, Utsunomiya University Center for Optical Research \\ \& Education (Japan) \\ Victor N. Zadkov, M.V. Lomonosov Moscow State University (Russian \\ Federation) \\ Weiping Zhang, East China Normal University (China)
}

Session Chairs

1 Quantum Sensing and Metrology

Roberto Osellame, CNR-Istituto di Fotonica e Nanotecnologie (Italy)

2 Quantum Measurement and Quantum Computation

Geoff J. Pryde, Griffith University (Australia)

3 Matter-Light Correlations and Coherence I

Xiaoying Li, Tianjin University (China)

4 Matter-Light Correlations and Coherence II

Hyunchul Nha, Texas A\&M University at Qatar (Qatar) 
5 Nonlinear Nanophotonics

Xiaolong Su, Shanxi University (China)

6 Ultrafast Nonlinear Optics and Frequency Conversion Kebin Shi, Peking University (China)

7 Microcavity Optics

Kebin Shi, Peking University (China) 